\title{
Gorgeous Tina's bloomers
}

\author{
BERNARD KNIGHT
}

The dangers of straying beyond one's own expertise are not confined to a doctor in the witness box. That most prolific of crime writers, the late John Creasey, once told me that his attempt to write a Western foundered on the ridicule received when he described "coyotes circling in the sky." What Dread Hand? suffers from a large number of forensic coyotes, as well as from a story line that is totally unbelievable, though that is common enough in thrillers. The book is one of a series revolving around Doctor Tina May, an equally unbelievable glamorous forensic pathologist cum TV personality. What makes her particularly incredible to this reviewer, himself a forensic pathologist and television writer, is that the beautiful doctor is said to net $£ 120000$ a year plus $£ 20000$ a show.

Dr May, who is never actually described by the author apart from the general glamour, goes on holiday to a Cornish village where everyone from the local general practitioner to the bobby belongs to an orgiastic witches' coven. Things start briskly with an amputated head being left in her cottage, removed as usual by "a skilled hand wielding a sharp knife." It had been deep frozen, but the dainty doctor, happening to have her necropsy bag on holiday with her, "puts on rubber gloves and opens the mouth" to look at the teeth. No mention of the crow bar that would actually be required.

When the next death occurs the holidaying doctor rushes off with her stethoscope (pathologist carrying a stethoscope?) and, again with rubber gloves and magnifying glass, diagnoses drowning. The necropsy is carried out by the local general practitioner police surgeon, which is par for the course for most crime novelists, who seem never to have heard of coroners' pathologists.

The sublime medical howler comes when the nosy woman goes to grill the general practitioner about his necropsy and says, "By the way, it was asphyxiation by drowning, I take it-and not suffocation?" Why don't writers do a little research, such as half an hour in the local reference library? I don't try to write books on hang gliding or kangaroo farming, so why do they think they can write on forensic pathology from their vantage point of abysmal ignorance?

The plot slogs on through the usual misapprehensions of Scotland Yard poking its nose into Cornish police affairs. More deaths occur and as the orgiastic general practitioner has been washed away in a flood by now the gorgeous Tina goes to the district general hospital to carry out eight necropsies-helped by a houseman seconded from his hospital duties. The mortuary (which contained within it the pathological department) had "lavishly equipped examination theatres" (in the plural) - and had "a magnificent modern cupola of frosted glass, beneath which was an examination table of extreme complexity, being capable of being tilted in any direction." It sounds as if Tina had strayed into the neurosurgical department to do her necropsies.

Of course this is all medical nit picking, and what matters is the plot and the quality of writing. The former is awful, but the writing is very good apart from a very strange habit which I have never seen before. In dialogue the author starts a new line with a new set of quotation marks when the same person is still speaking. We are all familiar with lengthy passages of dialogue where one has to count back to see who is saying what ... but it doesn't work in this book, and confuses the reader even more than the actual story.

The writing is what one would expect of the author, who is described on the dust cover as being of an "interesting age," of Trinity College Dublin and Cambridge, and the daughter of an Irish peer. Typically, the good lady makes her heroine travel to Cornwall in 1987 by the Great Western Railway.

It seems a pity that such competent English should be wasted on such a daft story with such a feeble grasp of how the police and real doctors deal with sudden death.

BERNARD KNIGHT

What Dread Hand? A Doctor Tina May mystery thriller. S Kemp. (Pp 192; £9.95.) London: Century, 1987. ISBN 0-7126-1458-3.

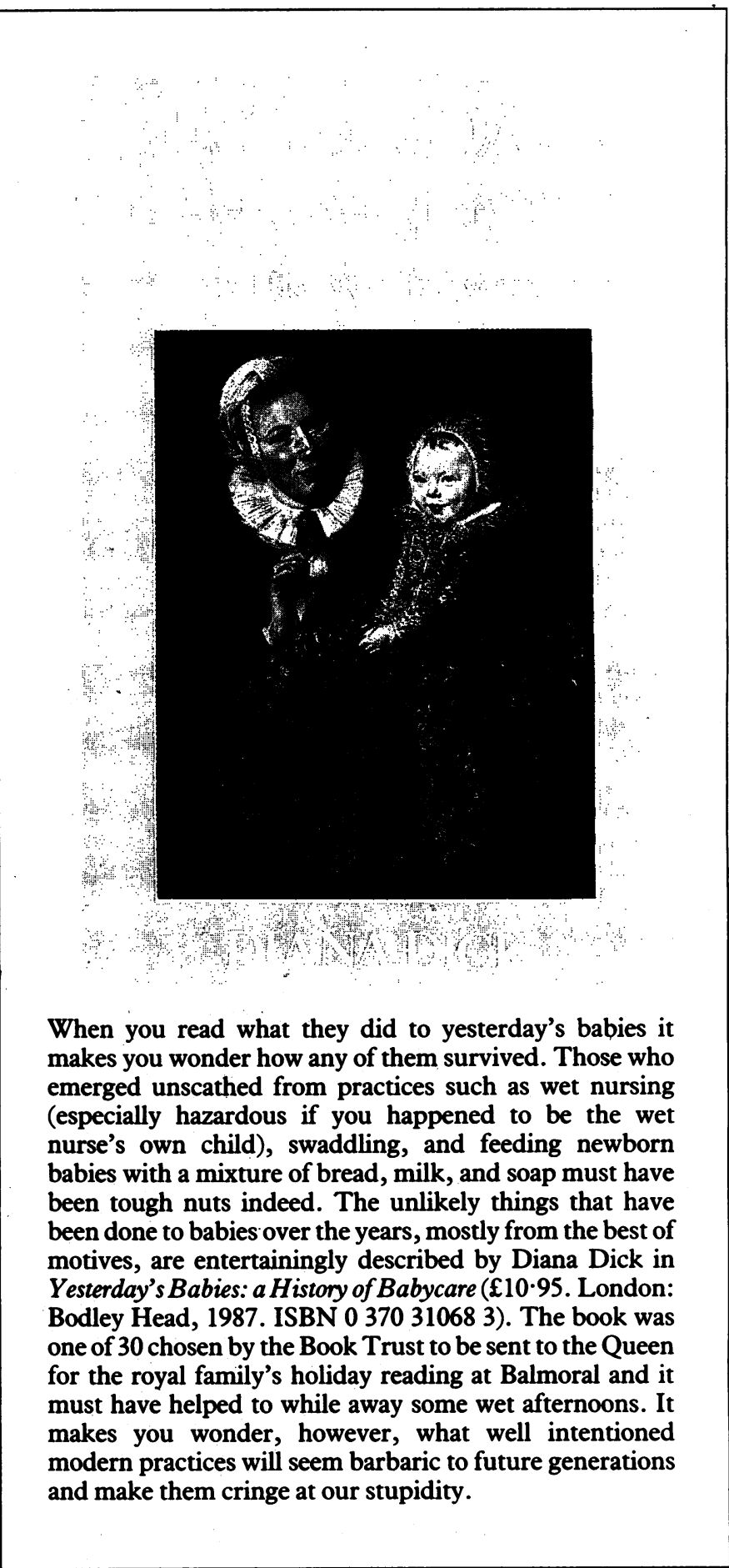

